January -2020

\title{
Constructing a Design Framework and Pedagogical Approach for Adaptive Learning in Higher Education: A Practitioner's Perspective
}

Thomas Cavanagh*, Baiyun Chen*, Rachid Ait Maalem Lahcen*, and James R. Paradiso* University of Central Florida

* The authors are listed alphabetically. All authors made equal contributions to the paper.

\begin{abstract}
While adaptive learning is emerging as a promising technology to promote access and quality at a large scale in higher education (Becker et al., 2018), the implementation of adaptive learning in teaching and learning is still sporadic, and it is unclear how to best design and teach an adaptive learning course in a higher education context. As early adopters, a team of instructors, instructional designers, and administrators at the University of Central Florida (UCF) identified five key design features as an adaptive learning design framework to guide the unique course design process. These five features involve deliberate design and development efforts that could bring significant benefits to student learning. The purpose of this field note is to present a design framework and best practices for teaching from both a systems and a pedagogical approach in the context of implementation at UCF. We also share the rationale and classification framework UCF has adopted to ensure the term "adaptive learning" is universally understood across campus. This paper offers insights into the design, delivery, and implications of utilizing adaptive learning systems in higher education courses at a public research university and attempts to capture the intimacy of lessons learned and best practices gathered since the project's inception in 2014.
\end{abstract}

Keywords: adaptive courseware, adaptive learning, course design, higher education, instructional design, learning analytics, mastery learning, personalized learning 


\section{Introduction}

Any cursory review of the digital learning marketplace or stroll through an EdTech conference exhibit hall will reveal the ubiquity of the term "adaptive learning." Whether the term refers to a specific platform, a publisher, or a pedagogical practice, it is clear that the last 5-10 years have seen a significant increase in its usage. But what does the term "adaptive learning" mean? As the usage of adaptive learning in higher education has advanced over the past few years, the research and practitioner communities seem to have coalesced around a few unifying concepts. For example, in 2013, the Bill and Melinda Gates Foundation launched the Adaptive Learning Market Acceleration Program (ALMAP) with nine platforms that "use learning model algorithms to track learner progress and recommend next steps in a learning path" (Yarnall, Means, \&Wetzel, 2016, p.5). Similarly, another initiative funded by the Bill and Melinda Gates Foundation, the Association of Public and Land-Grant Universities' (APLU's) Personalizing Learning with Adaptive Courseware explains that "(a)daptive courseware collects student data through assessment, analyzes that data and uses it to offer personalized learning paths to each student or reports and recommendations to instructors to help personalize the learning experience" (Association of Public \& Land-Grant Universities [APLU], 2017a, para.1).

However, with the increased attention and usage of the term "adaptive learning" there is also an increase in the inconsistency with which it is used. Due to its popularity and promotion by high-profile organizations such as the Bill and Melinda Gates Foundation, the term has also become something of a marketing buzzword. There are various adaptive learning systems available in today's educational technology market. For example, the Association of Public and Land-Grant Universities (APLU; 2017b) approved 21 adaptive courseware providers and products, with more and more companies in the marketplace using the term to promote their products. Unfortunately, their products do not all function in the same way and may not offer the same feature sets. They adapt learning in many different forms, yet are being labeled under the same umbrella term of "adaptive learning."

Adaptive learning remains elusive to define and continues to develop over time (Edsurge, 2016; Pugliese, 2016), and there are no specific guidelines or taxonomies for how the adaptive capabilities are described. Some adaptive systems providers classify their adaptive systems according to the instructional activities where adaptivity occurs: the content, the assessment, or the sequence as an integrated approach (Edsurge, 2016). Others classify the systems based on the underlying adaptive algorithm (Khosravi, Sadiq, \& Gasevic, 2020; Thompson, 2013). Pugliese (2016) categorized adaptive systems into four types: machine-learning systems, advanced algorithm systems, rule-based systems, and decision-tree systems (also see: Edwards et al., 2017). Yet, one specific adaptive algorithm is rarely identified with one system. As a matter of fact, many of the major adaptive learning players use a combination of the above adaptive algorithms in their systems. At the same time, these algorithms are often protected as proprietary commercial secrets. In such cases, even experienced users do not have the capabilities to decode the "black box" and understand the specific rules of the adaptive learning systems.

The matter of how institutions of higher education design and deliver adaptive learning courses (using a variety of adaptive platforms) to ensure program objectives are being met becomes a paramount issue and has been so at the University of Central Florida (UCF) as well. As UCF expanded its adaptive learning initiative, it became increasingly difficult to manage the many platforms that were either being considered 
for adoption or were already being used by faculty across campus. The companies behind these platforms (in many cases publishers) labeled their systems as "adaptive," yet the systems did not all function the same way. The underlying adaptive schemas differed, the feature sets varied, and the emphases between homework/ practice/ assessment and primary instructional content were not consistent.

Therefore, as its adaptive learning initiative grew from a few pilot courses to a more institutional scale, it became necessary to ensure that the courses labeled as "adaptive" all referred to the same basic functionalities. This was important for two primary reasons: (1) to make sure that students understood what they were registering for when they selected a course with an adaptive learning indicator in the schedule, and (2) to ensure that institutional evaluation efforts "compared apples to apples" when assessing the efficacy of adaptive learning regarding student success.

In order for UCF to credential a course as "adaptive" in its course catalogue, regardless of platform, the course must provide a minimum of three adaptive design features, with two other features listed as preferred (the UCF Adaptive Learning Design Framework). These features are, in the order of a design sequence:

1. The course consists of objective-based learning bits/ lessons.

2. It presents personalized content and assessments with timely feedback.

3. It offers an adaptive learning pathway that includes prerequisitelearning materials, an acceleration or remediation capability that adapts to students' knowledge, provides learning analytics, and recommends personalized interventions.

4. It presents alternative adaptive content presentation (video, text, etc.) based on learning performance and learning characteristics (optional but preferred criterion).

5. It procedurally generates questions and content using variables and conditions (optional but preferred criterion).

To answer the question of how to design and teach adaptive courses, this paper will expand upon each of the above five design features to provide institutional context and rationale and discuss the implementation of the design framework and pedagogical practices that maximize the benefits of adaptive technologies.

\section{The Digital Learning Context at UCF}

UCF has a long history of successfully delivering online and blended learning, which was initiated in the mid-1990s. In the 2018-2019 academic year, UCF generated more than $47 \%$ of its annual student credit hours in online and blended modalities. Digital learning at UCF serves both on- and off-campus students and includes an exclusively online virtual campus called UCF Online. The university's adaptive learning initiative, consequently, grew out of this foundation of digital learning success.

UCF currently recognizes six official course delivery modalities (Center for Distributed Learning, 2019): 
- World Wide Web - "W" courses are conducted via Web-based instruction and collaboration. Some courses may require minimal campus attendance or in-person/proctored examinations.

- Mixed Mode/Reduced Seat Time - "M" courses are blended and include both required classroom attendance and online instruction. Classes have substantial activity conducted online, which substitutes for some classroom meetings.

- Video Streaming - 'V" courses are delivered over the web via streaming digital video, which may be supplemented by additional online activity, projects, or exams.

- Video Streaming/Reduced Seat Time - In these "RV" courses, classroom-based content is available over the web via streaming video and classroom attendance is not required. Other required activities that substitute for video instruction may include any of the following elements: web activity, in-person or proctored examinations, and labs.

- Active Learning/ Reduced Seat Time - "RA" courses utilize Web-based learning technologies as the primary instructional medium within a blended course combining required face-to-face and online elements. Classes have substantial activity conducted online, and classroom activities are limited to no more than $20 \%$ of the instructional time over the course of the semester.

- Face-To-Face Instruction - " $\mathrm{P}$ " courses have required classroom attendance and meet on a regularly scheduled basis. Students may encounter online, video, or adaptive elements as part of the instruction, thus requiring a computer.

These modalities are coded into the university's student information system, allowing students to search for specific types of classes and theinstitution to track and evaluate by course type. Adaptivelearning design and technology may then be applied to any of these modalities as illustrated by Figure 1. The Personalized Adaptive Learning (PAL) indicator is a course attribute that can be individually searched for by students looking through the course catalog.

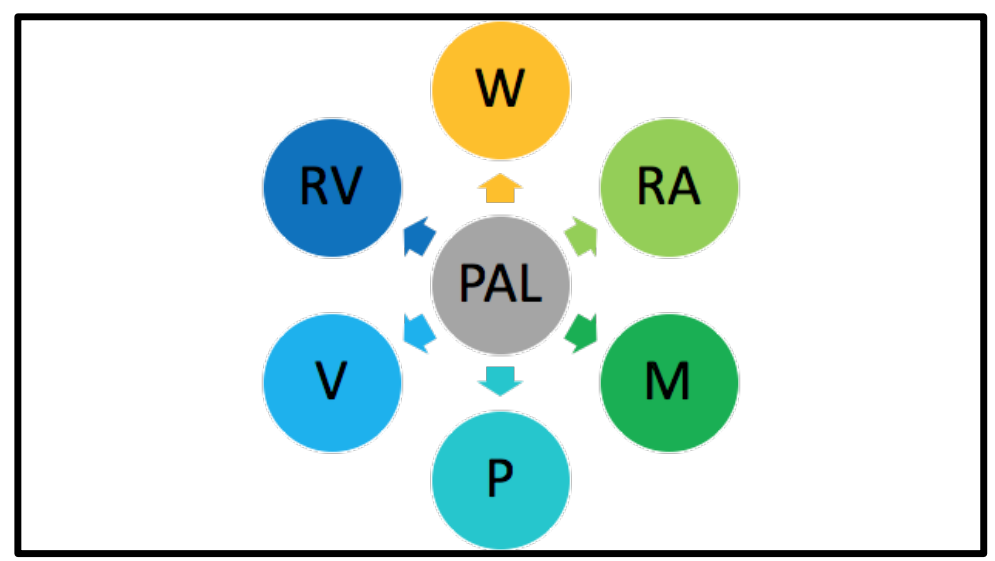

Figure 1. PAL course attribute supporting all six course delivery modalities.

In a PAL course, a portion of the overall instruction is delivered via an online adaptive learning system that customizes objective-driven content and assessments to create a personalized learning path for each 
student according to their knowledge, skills, and learning needs. PAL courses utilize one of several adaptive platforms that provides the previously defined adaptive design features. Some of the systems in active use on campus include Realizeit, ALEKS, Knewton Alta, and LearnSmart.

To support the development, delivery, and evaluation of its adaptive learning initiative, UCF established the PAL team. Consisting primarily of credentialed instructional designers, with assistance from technical and content experts, the PAL team is responsible for working with faculty to design and construct adaptive courses in all modalities, as well as support the course delivery and evaluation of its efficacy. In addition to direct faculty support through consultations, the PAL team may also assist faculty with course authoring within an adaptive platform, and this focus on faculty development and preparation has been key to the success of the university's adaptive learning initiative.

To further enhance the onboarding experience of faculty interested in designing and teaching an adaptive course, the PAL team has developed a training course called PAL6000. This self-paced course involves meeting with an assigned instructional designer at least six times, during the process of completing online course readings and a Build Your Course Project. The PAL6000 Certificate of Completion grants PAL credentials to design and teach using the Realizeit adaptive learning system. While a large percentage of certified PAL6000 faculty design their adaptive course(s) from scratch or some form of existing content, some alternatively adopt adaptive courseware from publishers. In these cases, the PAL team also partners with adaptive vendors to conduct workshops and ad hoc training for faculty to maximize the benefits of personalization and adaptivity for students.

Now that a contextual base has been established, the remainder of this field note focuses on the design, delivery, and implications of utilizing PAL systems at UCF, capturing the lessons learned and best practices gathered since the first adaptive pilot in 2014.

\section{An Adaptive Learning Design Framework}

At UCF, many instructors choose to design their adaptive courses with self-authored content, open educational resources (OER), or publisher content. This is primarily due to the lack of existing adaptive courseware in most disciplines. When designing these new adaptive learning courses with individual faculty, the PAL instructional designers follow a systems approach using the five key adaptive design features-the Adaptive Learning Design Framework-as displayed in Figure 2. The first three design features are required components of any PAL designated course, while the last two (although not required) add important value to any PAL course experience. The designers work with instructors to incorporate these five features into course design. (These five design features will be discussed in further detail in the following sections). 
Figure 2. UCF's adaptive learning design framework with five key features.

\section{Objective-Based Learning Bits}

Defining specific learning objectives as a "first-step" in adaptive course-design establishes the parameters by which a variety of content-trajectories can converge, diverge, and/ or repeat (Willcox \& Huang, 2017). In the process of authoring adaptive content, as a best practice, UCF course instructors, as the subject matter experts (SMEs), are guided to identify small knowledge units, called learning bits (i.e., lessons) that typically take students an average of 30 minutes to complete. This content structuring process typically takes on the form of breaking one learning objective into five or more concepts. For instance, instead of delivering 14 fully intact chapters of content, UCF's PAL courses might contain up to two hundred mini lessons derived from those 14 chapters where students are evaluated frequently (e.g., at the end of each lesson) to measure the level of mastery they have achieved related to one or more learning objectives.

Suppose one course objective reads as follows: "Students will be able to use simple linear regression as indications and trends of business and economic data" (Buhagiar, 2018). To support this objective, 10 lessons (Figure 3) on concepts or component skills are identified and mapped back to that objective in the form of evidence-bearing assignments and/or assessments, which are then measured individually and collectively by the PAL system to determine which content and/or assessment item(s) to deliver next to increase the students' likelihood of achieving mastery on that objective. 


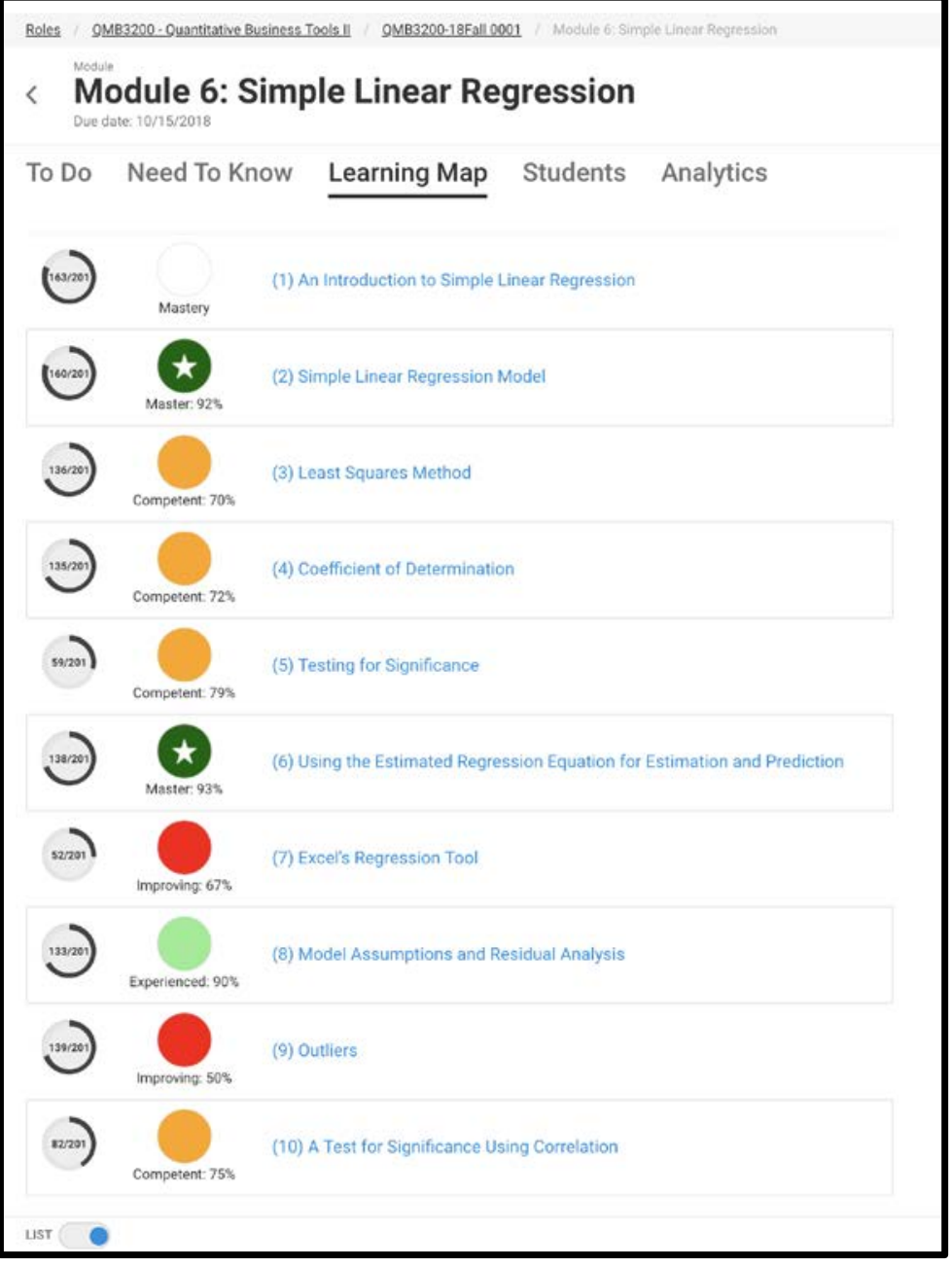

Figure 3. Ten lessons associated with the objective on the topic of Simple Linear Regression. Adapted from QMB3200: Quantitative Business Tools II, by T. Buhagiar, 2018, Orlando, FL: University of Central Florida. Copyright 2018 by the University of Central Florida.

\section{Personalized Assessment and Content}

After specifying learning bits or lessons at the concept or component skill level, the courseware authoring process involves drafting content materials, assessment items, and detailed feedback. The majority of adaptive systems are assessment-driven (Essa, 2016) as the platform delivers personalized instruction based on the results of pretests/posttests and practice and/or graded assessment(s). Compared to traditional online courses, an instructor spends considerably more time developing assessment items and feedback than writing content. During the process of designing an adaptive course, after the learning objectives are granularized, an instructor would likely identify learning bits that lack assessment items from the existing question pool, as it is recommended that each adaptive lesson includes at least five or more questions. The more questions a lesson includes, the more robust the learning experience. In some of UCF's completed adaptive courses, for example, instructors expanded their question pool from a couple of hundred (maybe 20 per chapter) to over 1,000 for the entire curriculum. 
Writing detailed feedback is another key element in adaptive course design. Students improve their performance through continuous practice, feedback, correction, and enrichment in the formative assessments of each lesson. Students need to practice with timely feedback in order to identify specific areas they may need to improve. Therefore, instructors are highly recommended to write detailed feedback at the question level to scaffold student learning. This feedback could include the correct answer, why a particular response/ option is correct (or incorrect), or recommendations of topics for the student to review (Chen, Bastedo, Kirkley, Stull, \& Tojo, 2017). Figure 4 illustrates an example question (Chen, 2019) from an adaptive course with detailed feedback for both correct and incorrect responses.

Select the statement that best describes a condition.

When given a group of spelling words the students will be able to put them in alphabetical order.

Fifth grade students will be able to state the six state capitals with $100 \%$ accuracy.

Solution

Correct choice(s):

When given a group of spelling words the students will be able to put them in alphabetical order. This tells the learner that a group of spelling words are going to be given to them. They are not expected to decide what the spelling words are. You remembered that the condition states what the learner will be allowed to use.

Incorrect choice(s):

Fifth grade students will be able to state the six state capitals with $100 \%$ accuracy. "Be able to state" is a behavior not a condition. It is important to remember that when we are dealing with a condition. The condition states the available resources. The correct answer would have been: "When given a group of spelling words..." The resources here are the spelling words. The student is told that they will be given the resources and will not have to decide what the spelling words are. A condition can state the situation and setting for the performance to take place. Remember that the condition can tell the cue or stimulus used in a performance objective. The condition states what the learner will be allowed to use.

Figure 4. Detailed feedback for each assessment item. Adapted from EME6613: Instructional Systems Design, by B. Chen, 2019, Orlando, FL: University of Central Florida. Copyright 2019 from the University of Central Florida.

To meet each student's unique learning needs, a large number of learning activities must be developed and tagged, which creates significant workload for faculty SME and instructional designers (Khosravi, Sadig, \& Gasevic, 2020). While the design and development work are time-consuming, this phenomenon is rarely 
reported in the literature (Baker, 2016; Essa, 2016). However, when reported, such as in the case of Pavlik Jr., Brawner, Olney, \& Mitrovic (2013), an estimate of 200 hours of development time was estimated to be spent for every one hour of instructional content design. In another study (Aleven, Mclaren, Sewal, \& Koedinger, 2009), with the use of smart tools, it took the SME alone 25 hours to author one hour of content. At UCF, each PAL instructional designer actively works with two to five faculty members who focus on completing one or two adaptive modules (objectives) each semester; therefore, due to resource limitations, one adaptive course might take six or more academic semesters to complete.

\section{Adaptive Learning Path}

The assessment-driven learning bits that were authored during the content development phase are then mapped into a hierarchical structure to ensure students master prerequisite skills before proceeding to more advanced topic areas in the hierarchy. The adaptivity starts with knowledge determination (in the form of a pre-determined set of questions) to allow the system to gather information about the students prior to having them engaging in the core material. As a caveat in regard to "pretesting," the degree to which an adaptive system can be configured varies across platforms. Pretesting determines preliminary questions a student sees, and based on students' performance, an adaptive system determines students' acceleration or remediation through the objective-based learning pathway. It is a very valuable system functionality for an adaptive system to determine students' knowledge prior to moving forward to their core learning task(s), particularly if it is developed thoughtfully.

To a varying extent (depending on the system), a learning path with feedback/ remediation can be constructed, but the adaptivity only exists in theory until an agent (in this case a student) enters the system and interacts with it. At that point, the system begins to gather data about the learner-primarily structured around content preferences (possibly identity) and proficiency level. These bits of information then power the type and/ or difficulty-level of material(s) a student encounters, and as thelearner-profile begins to form related to the aforementioned items, the instructor can analyze those learner-centered data trends and intervene as appropriate to encourage content review and revision-reinforcing student mastery. Figures 5a and 5b illustrate two learning paths based on different adaptive course designs at UCF.

Figure 5a illustrates several initial modules (objectives) of a business statistics course built in Realizeit. This portion of the learning path consists of 25 learning bits (lessons) on six color coded topics. Students start the learning path from left to right, and subsequent lessons can only be unlocked if prerequisite lessons have been completed. This type of mapping allows space for students to choose their pathway (e.g., down the p-bar or x-bar route), while applying enough foresight (design-wise) to limit students to the materials they are prepared to engage with during particular points along the learning pathway(s). 


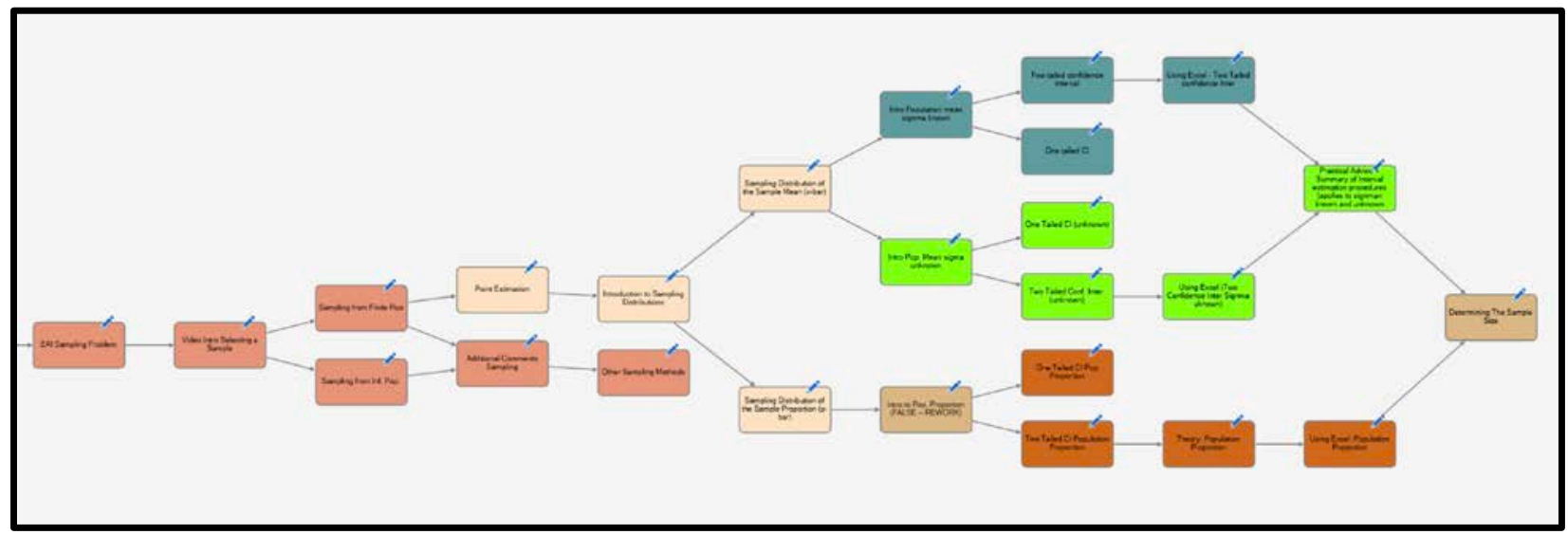

Figure 5a. A portion of a Realizeit learning path in QMB3200 (modules 2 and 3). Adapted from QMB3200: Quantitative Business Tools II, by T. Buhagiar, 2018, Orlando, FL: University of Central Florida. Copyright 2019 from the University of Central Florida.

Figure 5b represents an example learning pie in ALEKS. The slices are color coded and represent the chapters in the domain or course curriculum. The number of instructor-selected topics in each slice is shown below its title. In this example course, those chapters are divided into 14 weekly custom objectives and each objective contains 20 topics. Custom objectives are used for weekly pacing throughout the curriculum. ALEKS organizes those topics in a "Ready to Learn" category based on previous learned and mastered topics. In Figure 5b, the student is at objective 4 called "Obj. 4 2.1-2.3" and has 12 more topics left to learn. The next topic to learn on the learning path is "Variable expressions as inputs of functions: Problem type 1." 
UP NEXT :

Variable expressions as

inputs of functions:

Problem type 1

\section{CONTINUE MY PATH}

WORKING TOWARD

Obj. $42.1-2.3$

12 of 20 Topics

Due: Friday 11:59 PM

ALEKS Pie Goal

120 of 213 Topics

Due: Dec 8

WORK ON SOMETHING ELSE

Practice Test 1 (full retake,

unlimited)

Due: Today 11:59 PM

Attempts: 1 of Unlimited Attempts
Cavanagh, Chen, Lahcen, and Paradiso

\section{(a)}

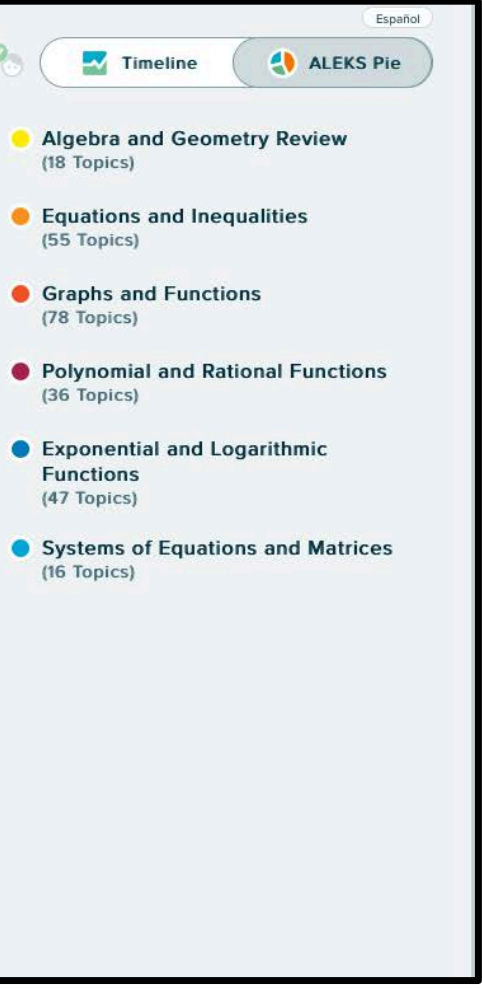

Figure 5b. A sample of the ALEKS learning pie. Adapted from MAC1105C: College Algebra, by R. Ait Maalem Lahcen, 2019, Orlando, FL: University of Central Florida. Copyright 2019 from the University of Central Florida.

Learning analytics is another key component of the adaptive learning path. It is not a design feature but a key teaching feature once the instructor starts to teach with an adaptive system. In a number of courses at UCF, adaptive courseware delivers a robust web of content with personalized feedback that results in granularized data points for each student, which can then be acted upon by the instructor(s) in real-time. How long has a student spent in a given learning space, and how much effort has been expended during that time? Has this student flagged any questions for review or made continuous attempts at certain questions to no avail? This can be viewed at the aggregate (class) level and domain level as well, and what is particularly helpful in each scenario is if an instructor actually possesses the flexibility to engage differently (based on that feedback) in the next face-to-face session, online component, office hours, or even email and/ or a class announcement. This type of student-centered learning analytics can be used to create peer/mentoring groups and provide any other type of intervention before this academic concern becomes either irreparable or very challenging to resolve. Detailed examples of learning analytics are presented in the Pedagogy section of this paper.

The success of this adaptive pathway depends on the instructor and a few main system functionalities: prerequisite mapping, assessment variability (textual and numeric components), content preconditions, and alternative learning modalities (textual, interactive, multimedia). The latter of which will be expounded upon in the next section. 


\section{Alternative Content and Choices}

In the process of organizing content into learning bits (lessons), UCF PAL instructors and instructional designers found that relative to traditional courses, adaptive courses need additional or alternative content (Chen et al., 2017). This feature is not discussed widely in adaptive learning literature (as far as the authors have observed), but anecdotal feedback indicates this enhancement augments the adaptive personalization of adaptive courses. For example, in adaptive courses with alternative content (Figure 6), the system will ask students if they would like an alternative version of an example or instruction during a lesson path.

\begin{tabular}{|l|l|l|}
\hline 1. Introduction & $\begin{array}{l}\text { such integrated materials. } \\
\text { Access code to kick off project - open file: code for Project } \\
\text { Link to external article for review - Scientific Paper }\end{array}$ \\
\hline 2. Learning & $\begin{array}{l}\text { The learner can get alternative content. } \\
\text { 3. Example }\end{array}$ \\
\hline 4. Questions & $\begin{array}{l}\text { Just as there is no one right way to teach an entire class, there is no one right piece of content that } \\
\text { will work for every student. Realizeit supports the use of alternative content on every knowledge } \\
\text { item. That is, multiple sources of content can be used to teach the same concept. When available, } \\
\text { Realizeit will automatically select the most appropriate source as the student begins learning. } \\
\text { However when the student is done with that content, the system will ask the student if they are } \\
\text { happy or would like to see an alternative. Realizeit learns which types of content work for students } \\
\text { and when. }\end{array}$ \\
\hline 5. Summary & $\checkmark$ \\
\hline & Would you like an alternative version of this content? \\
\hline
\end{tabular}

Figure 6. An example of a Realizeit lesson with alternative content.

The alternative content could be a video related to the content students have just read or another practice example with different variables. Due to time and personnel limitations, alternative content or choices are developed in only a select number of UCF adaptive courses, but as more instructors have now completed their initial design, this is a prioritized feature in their course revision agenda.

Prior to pursuing adaptive course design and development, instructional content in the Learning Management System (LMS) at UCF often consisted of PDF documents, PowerPoint slides, and some basic Web-based content pages. To evolve from the traditional course building model to an adaptive one, instructional designers, along with multimedia specialists and course instructors, have enhanced the content with additional text, detailed examples, embedded videos, animations, and other resources (Chen et al., 2017). By doing so, the institution found a novel way to accommodate diverse student learning preferences and incorporate learning principles for universal design (CAST, 2018). For instance, having a variety of question sets, examples, and multimedia increase the level of content variation for students who revisit lessons to engage with the learning materials. 


\section{Procedurally Generated Questions}

While content and assessment development can be arduous and time-consuming, their payoff is in the potentiality of constructing a personalized (contextually relevant) and adaptive (evolving) learning experience. This adaptive experience can be further enhanced through leveraging content variables, groupings, and conditions.

Regarding content variables, groupings, and conditions, there are a few noteworthy examples from within the UCF PAL ecosystem. One that stands out is a set of mathematical (word) problems that have strings of variables for male and/ or female names and a completely different scenario depending on a student's major (e.g., business, education, etc.) so each student will access content that is relevant to learner's background and characteristic (Muhs, 2018). This same design feature is applied to quantitative aspects of the course as well, where numbers are randomly generated (within predefined thresholds) for practice problems and other numeric assessments (including advanced data analysis using Microsoft Excel). Grouping and conditions are closely related and can be looked at simultaneously and, depending on the flexibility of the adaptive learning system, groupings of questions can also be set up to manifest upon certain conditions. These conditions might relate to the variables of a given problem or case study and even to specific values appended to learning content so the content only appears under specific numerically defined circumstances (e.g., less than or equal to a score of $70 \%$ on the last assessment will offer learning item 1 , whereas a score greater than $70 \%$ will offer learning item 2 ). Figure 7 presents a case study with embedded variables from a nursing undergraduate course. Each student is presented with a unique case study with varying correct answers and feedback. Students are motivated to practice the case study multiple times because a different case study is presented for each attempt. 


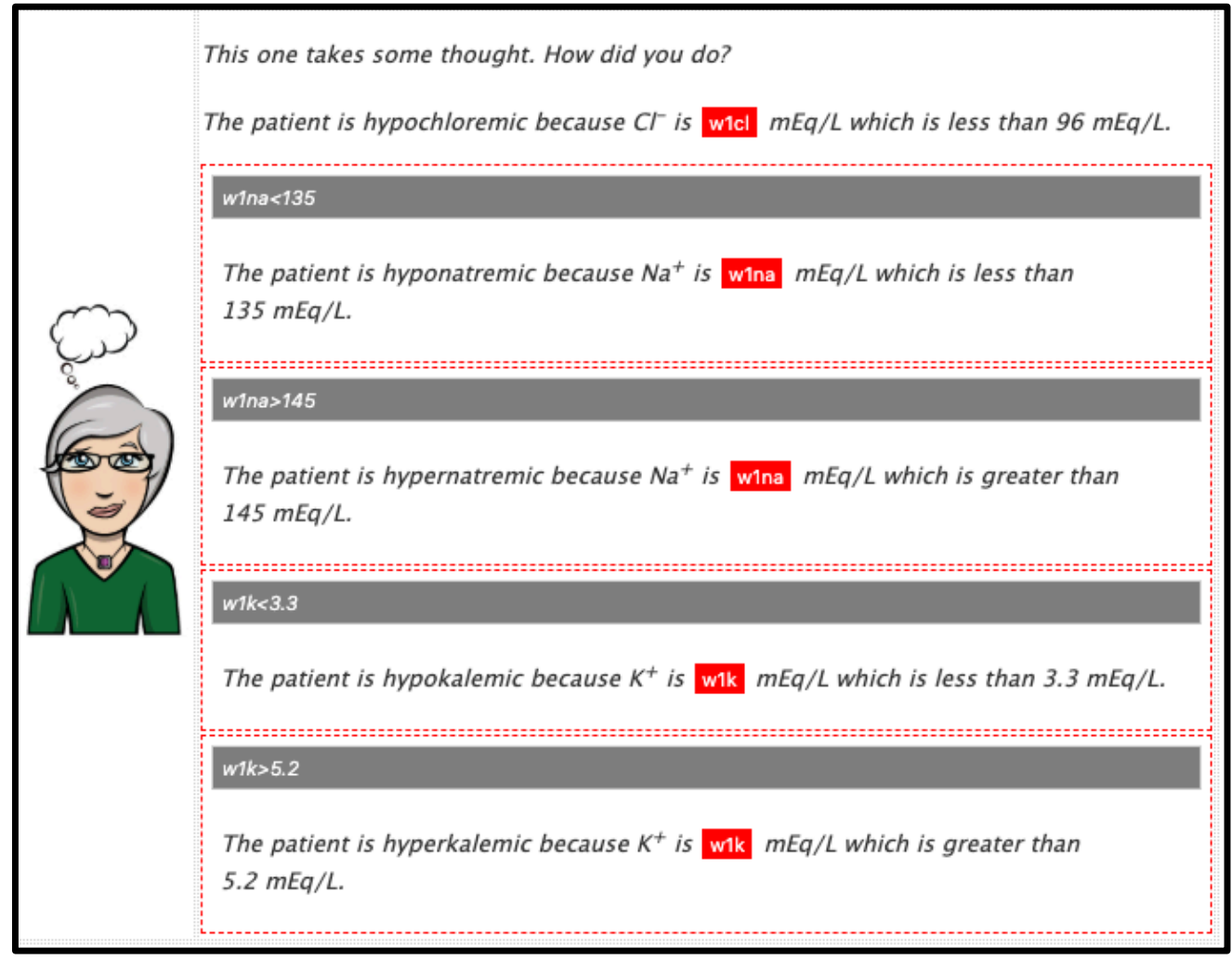

Figure 7. An example of an adaptive case study with varying feedback that embeds numerical variables. Adapted from NUR3125: Pathophysiology for Nursing Practice, by J. Hinkle, 2017, Orlando, FL: University of Central Florida. Copyright 2017 from the University of Central Florida.

The five adaptive design features listed above can be arranged in a myriad of complex ways, but the content area itself (and the amount of content available), along with the subject matter expert/ instructor and design team, may afford or restrict the adaptive system capacities due to a lack of systems expertise or simple time constraints. That being said, adaptive systems are continuously evolving, so the more involved a design team is with the build process - communicating directly with the software company, offering feedback, and proposing feature requests - the more willing these educational technology companies are to stretch and expand to create new and innovative ways to provide meaningful adaptive learning solutions.

\section{A Pedagogical Approach}

Regardless of the instructors' choice to create their own adaptive content or adopt existing courseware, teaching with an adaptive platform involves deliberate planning and management, and the importance of an instructor in the use of an adaptive platform cannot be stressed enough. Therefore, adaptive pedagogy is highlighted in our faculty training process to make sure instructors use the system, not only as a homework system, but also as an integrated instructional tool to improve student learning. The following sections discuss the best practices for teaching with adaptive technologies. 


\section{Change of Perspectives: From Lecturing to Personalization}

As the literature (Chen et al., 2017; Dziuban, Moskal, Johnson, \& Evans, 2017; Dziuban et al., 2018; Essa, 2016) suggests, adaptive learning is often linked with terms such as personalized learning, mastery-based learning, and student-centered learning. Unlike traditional lecturing, adaptive instruction is dynamic and personalized to meet the unique needs of individual learners. Since students come with different knowledge sets, the intention of adaptivity is to help each of them reach a desired level of mastery at their own pace by allowing them to be active and independent learners instead of passive listeners in traditional lectures. Adaptivity is achieved by determining individual's prior knowledge and providing personalized learning recommendations. In adaptive courses, instructors release control of certain aspects of instruction, leaving some of the responsibility in the hands of students.

One of the misconceptions that comes with the adaptive system is that the technology will replace instructors in schools. Although adaptive technology facilitates the students' learning process, the successful implementation of adaptive learning still requires human planning, interactions, monitoring, and interventions. The role of an instructor remains crucial (Baker, 2016; Brusco, 2018; Essa, 2016; Essa \& Laster, 2017) in adaptive learning because only the instructor can select learning objectives that fit with the overall course learning outcomes and targeted student population, align both online and face-to-face activities and assessment with selected learning objectives, orchestrate learning activities both online and in person, and provide individualized feedback and support for all learners (Essa \& Laster, 2017). The instructor organizes various additional class activities around the adaptive practices, sets up course expectations and grading schemes, monitors students' progresses, and answers questions. It is the instructor's responsibilities to assist students in understanding the functionalities and the value of the adaptive system, and to help students transition from passive learners to active collaborators so they can begin to understand the rationale why frequent assessments provide guidance instead of hindrance to their progress. This level of awareness is critical, as Deslauriers, McCarty, Miller, Callaghan, \& Kestin (2019) so aptly convey: A lack of timely instructor communication will result in student resistance and learner disengagement.

\section{Understanding the Adaptive System: Getting Ready to Teach}

For instructors who adopt existing adaptive courseware, the first step is to understand what an adaptive system is and evaluate existing adaptive courseware to select the one that most supports the course learning outcomes. Some of the questions that the instructor can ask during the evaluation process include: Is it simple to navigate? Does it integrate with the institutional LMS? Is it compliant with the Americans with Disabilities Act (ADA)? How does it make learning recommendations to students? Does it provide good explanations and ample resources? Can the instructor customize, add, or edit content and questions? What kind of instructor and student support will the company provide? A complete list of technology evaluation criteria can be found on the Courseware in Context website. If none of the existing adaptive courseware suffices, the instructor still has the option to create their own adaptive courseware using an adaptive platform that permits original or $3^{\text {rd }}$-party content to be integrated.

After selecting the courseware, it is essential for the instructor to take some time to learn how the adaptive system supports student learning, enlisting the support of publisher representatives and instructional designers as necessary. Only with a thorough understanding of the system will the instructor be able to 
select relevant content, take advantage of the system adaptivity, and remedy any existing system limitations with instructor-made supplementary resources and class activities. After the instructor understands how the system works and what content and questions the system offers, he/ she can then help the students build trust in the system's recommendations, select objectives and learning activities that meet students' needs, and prepare additional learning materials that might be missing from the adaptive courseware.

In an adaptive course, instructors should provide students with an overarching picture of how the course works to help them understand and manage the workload. Most likely, adaptive assignments have a nontraditional grading scheme where scores are calculated based on a combination of factors, such as learning performance, time spent, effort, speed, and other data points. Again, it is the instructor's responsibility to help students translate the scores and guide them in the right direction to maximize their learning efforts. Confusion about grading schemes could easily result in low student motivation, which will lead to poor learning performance.

\section{Teaching With Adaptive Learning: Class Management Strategies}

At the beginning of the semester, in adaptive courses, instructors should present clear syllabus documentation with explicit assignments, grading policies, and criteria for advancing if students are allowed to complete the course early to advance into the next class. In addition to a clear syllabus, we highly recommend that instructors prepare a syllabus quiz for students to complete so they read the syllabus carefully and do not miss important information.

As most of the adaptive assignments are self-paced individual learning activities, instructors should make recommendations to guide self-paced learning so learning is effective. As the learning path for each student is personalized, some students might have more objectives to learn or master than others. Thus, it is important to allocate adequate time for those students to learn and reflect before important milestones. In the situation where students pace their own learning, some might procrastinate and fall behind due to various reasons. Therefore, it is essential for instructors to intervene with reminders and online or inperson mentoring opportunities and to allow for extra time on milestone tests and reasonable opportunities for students to catch up.

It is critical for instructors to become knowledgeable about learning analytics presented in the adaptive system, as indicated in Figure $8 \mathrm{a}$ and 8b. Student-centered learning analytics, including learning rates/speed, login frequency and time, student progress, and learning performance, can offer insights to help instructors understand their students. An early progress feedback alert system can greatly help students focus on their tasks. For instance, instructors can set up automated reminders based on inactivity or abnormal learning rates. It is a good practice to check in with students with abnormally slow or fast learning rates to avoid procrastination or potential cheating/gaming practices. 


\begin{tabular}{lllll} 
Last Login & Enroll Date & $\begin{array}{l}\text { Hours per Week } \\
\text { At Institution }\end{array}$ & $\begin{array}{l}\text { Total Time in this Class } \\
\text { At Institution }\end{array}$ \\
\hline $04 / 30 / 2019$ & $01 / 08 / 2019$ & 2.9 & 1.2 & 46h $4 \mathrm{~m} \quad 19 \mathrm{~h} 11 \mathrm{~m}$
\end{tabular}

\section{SP 19 MAC1105C - 1 TR 08:30AM Dan (Current Class)}

All Classes

$$
\text { Knowledge Checks }
$$

Reason

Start

Finish Performance

Since Last Knowledge Check

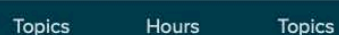

Topics

ALEKS per Hour

SP 19 MAC1105C - 1 TR 08:30AM Dan (Current Class) - 280 Topics - Instructor Lahcen

Comprehensive Assessment

Assigned Knowledge Check -

Comprehensive

Progress Knowledge Check

Progress Knowledge Check

Pross Knowledge Check

Progress Knowledge Check

Progress Knowledge Check

Progress Knowledge Check

Initial Knowledge Check

\begin{tabular}{ll} 
Apr 23 & $\begin{array}{l}\text { Apr 23 } \\
\text { 1h } 4 \mathrm{~m}\end{array}$ \\
& \\
\hline Apr 23 & $\begin{array}{l}\text { Apr 23 } \\
34 \mathrm{~m} \mathrm{22s}\end{array}$ \\
&
\end{tabular}

Mar 19

Mar 19
$24 \mathrm{~m} 35$ $24 \mathrm{~m} 35 \mathrm{~s}$

Feb $11 \quad$ Feb 11 $30 \mathrm{~m} 32 \mathrm{~s}$

Jan $29 \operatorname{Jan} 29$

$19 \mathrm{~m} 45 \mathrm{~s}$

$\begin{array}{ll}\operatorname{Jan} 21 & \operatorname{Jan} 21 \\ 38 \mathrm{~m} 3 \mathrm{~s}\end{array}$

Jan $8 \quad \operatorname{Jan} 10$

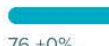

$76+0 \%$

$64+0 \%$

$55+12 \%$

$43+20 \%$

$34+9 \%$

$24+10 \%$

$\square$

$18+11 \%$

Figure 8a. Progress report (ALEKS) shows student progress knowledge checks, topics learned, hours in the system, and learning rate. Adapted from MAC1105C: College Algebra, by R. Ait Maalem Lahcen, 2019, Orlando, FL: University of Central Florida. Copyright 2019 by the University of Central Florida. 


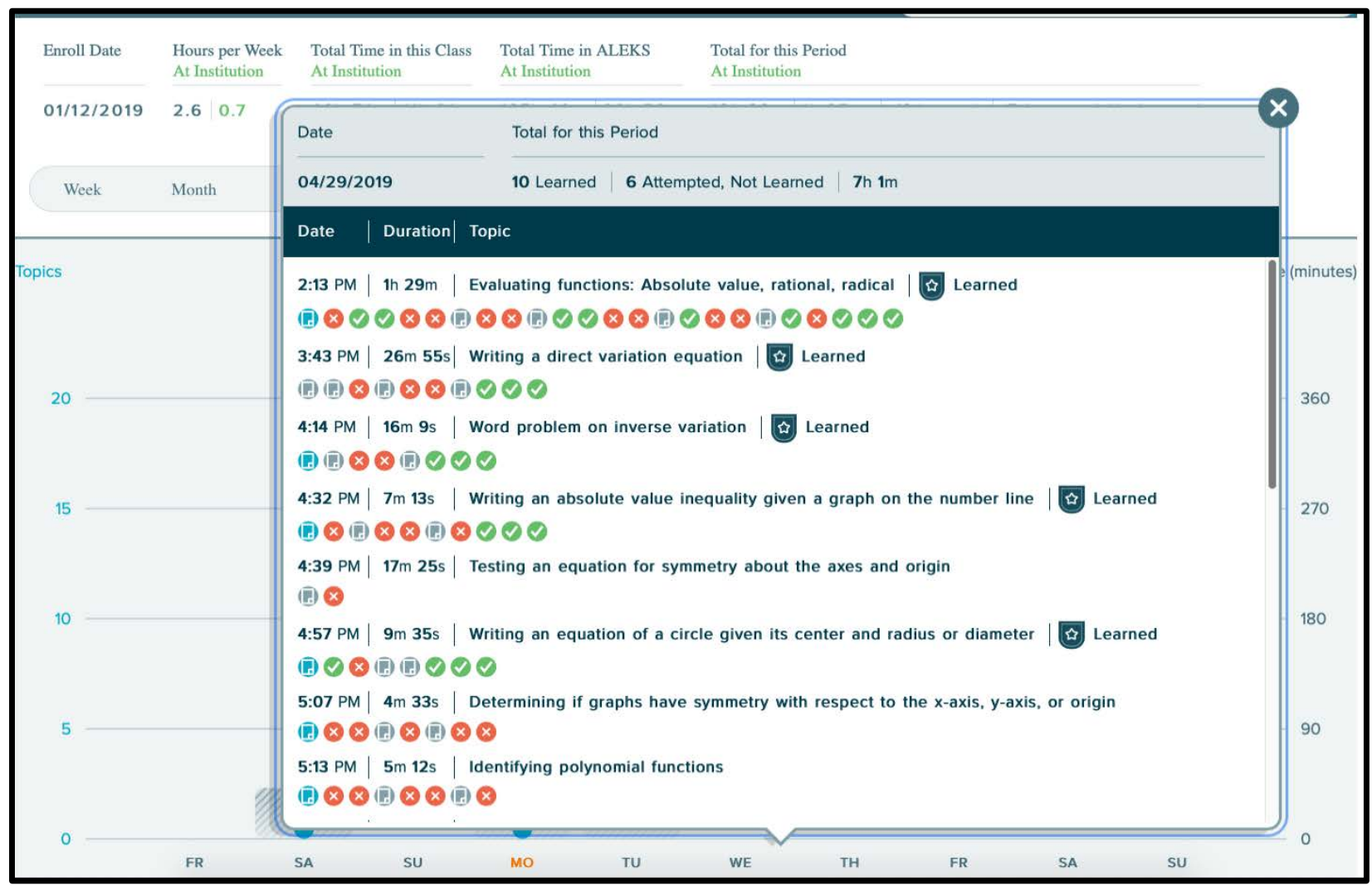

Figure 8b. Time and Topic (ALEKS) show the actions of the student in the learning path. This snapshot shows that on April 29 the student failed to learn three topics (attempted, but didn't learn). The instructor can see that the student accessed the explanation page before the last attempt. The student's answers are recorded and can be referred to when the instructor meets with the student for one-on-one tutoring. Adapted from MAC1105C: College Algebra, by R. Ait Maalem Lahcen, 2019, Orlando, FL: University of Central Florida. Copyright 2019 from the University of Central Florida.

Domain-centered analytics (Figure 9a and 9b), on the other hand, can help instructors identify problem areas and improve their teaching practices. Effective instructors should take a concept-based flexible teaching method. Traditional lecturing to a whole class while students are on different learning paths contradicts the purpose of adaptive learning. Instead, based on system analytics that show students' weaknesses, instructors can prepare small chunks of supplementary materials and activities to target problem areas. 


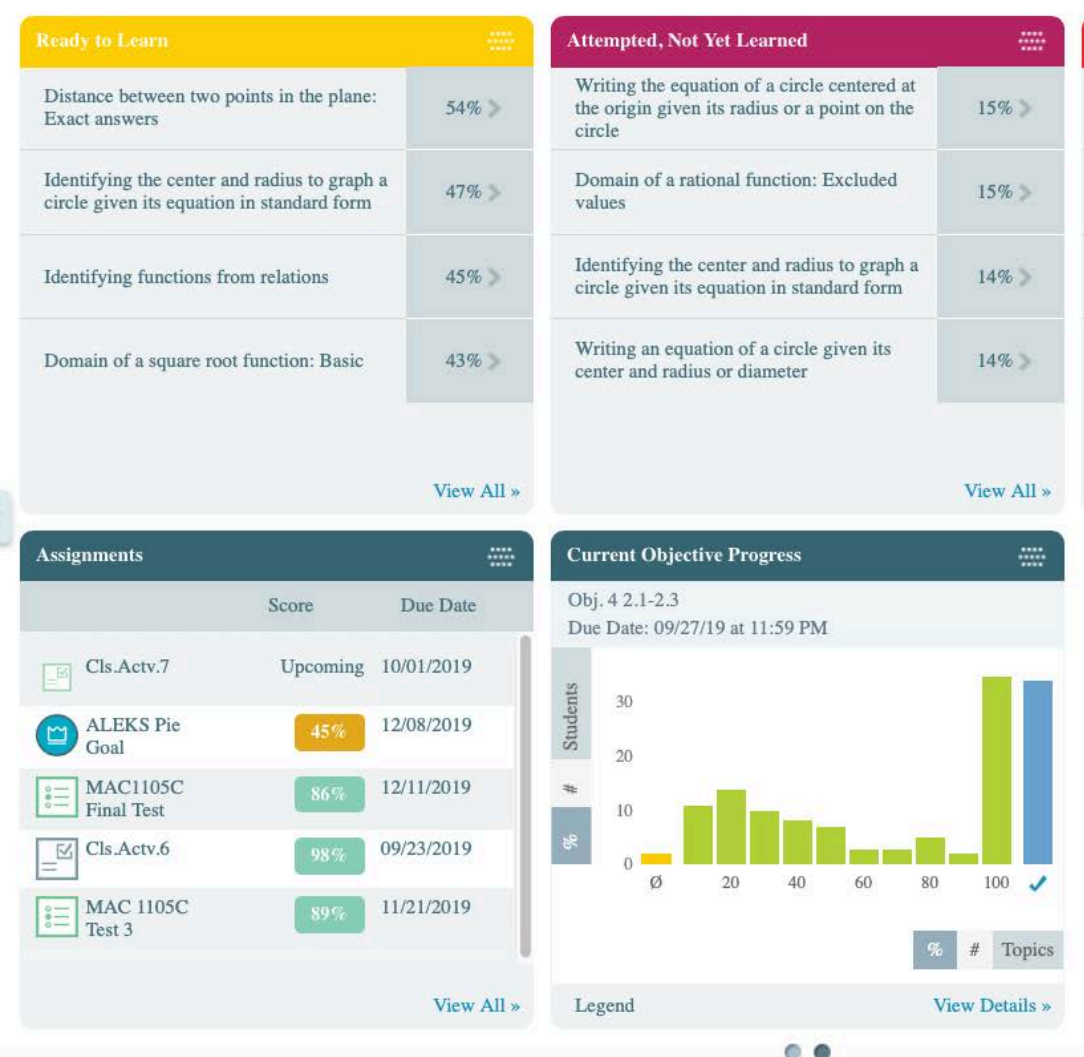

Figure 9a. Tiles on dashboard (ALEKS) offer analytics at the course section level. Each one can be expanded for details on the group of students that lost topics on a most recent assessment, attempted a topic but didn't learn, or weren't ready to learn certain topics. Adapted from MAC1105C: College Algebra, by R. Ait Maalem Lahcen, 2019, Orlando, FL: University of Central Florida. Copyright 2019 by the University of Central Florida. 


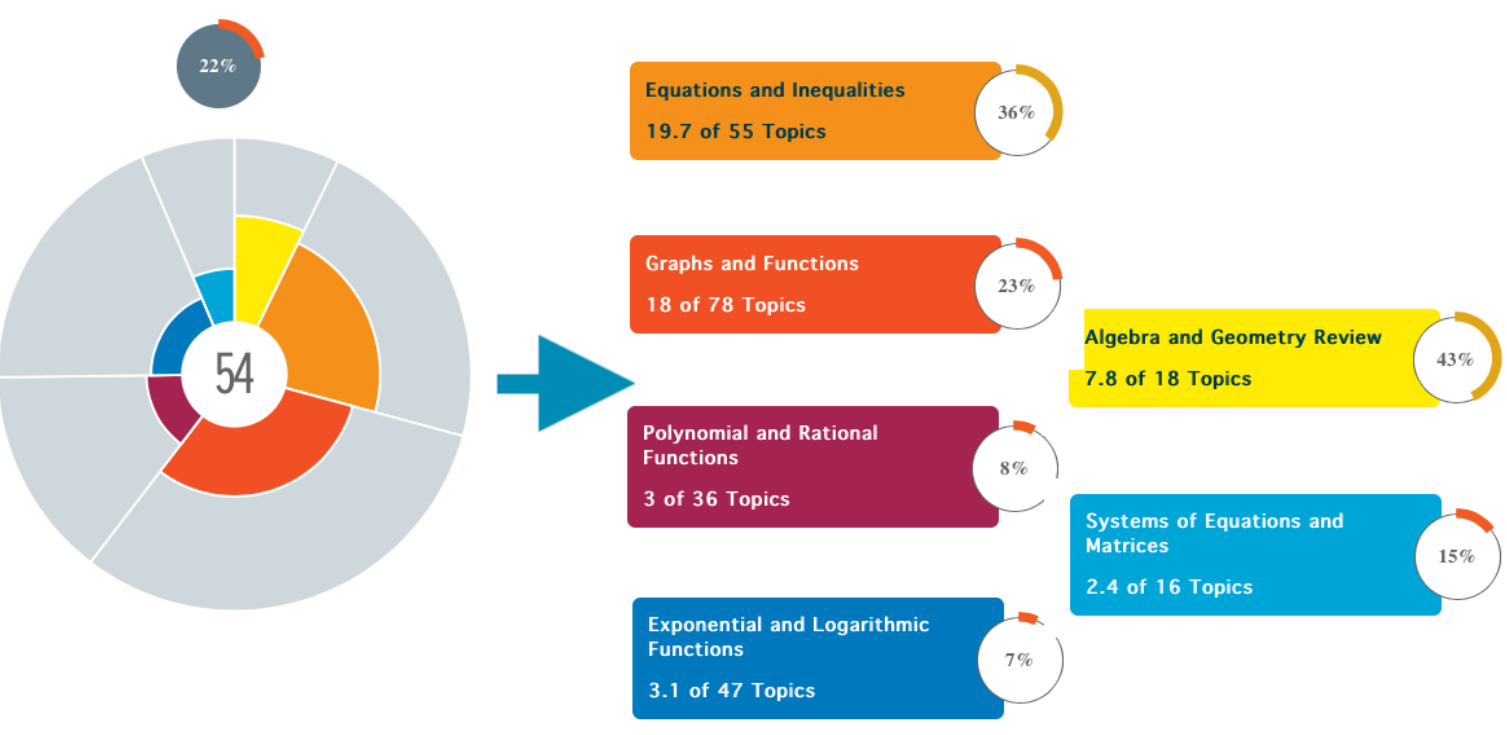

Figure 9b. The Pie report (ALEKS) illustrates students' mastering information after the initial knowledge check. The instructor can build on this baseline in follow-up class meetings or online communications. Adapted from MAC1105C: College Algebra, by R. Ait Maalem Lahcen, 2019, Orlando, FL: University of Central Florida. Copyright 2019 by the University of Central Florida.

As instructors review the students' performance and interact with them, it is easy to identify learning gaps, misconceptions, and challenging concepts among students. Depending on the results from these dashboards, instructors can prepare in-class mini-lectures, small-group discussions, or workshops to provide additional support for groups of students with common difficulties. Figure 10 documents an example of a mini-lecture and how it is delivered for students with low mastery of compound inequalities in the College Algebra course. For specific groups or students, instructors can also offer individualized cumulative reviews to help them set up connections between prior knowledge and new concepts. Providing automated and instructor-led feedback adds tremendous values to the adaptive learning process. 
Mini-Lecture example 1: Since data analytics show that students come with low mastery of compound inequalities (\#3 and \#4) we indetified the problem to be more of the the solution interpretation than the algebraic manipulation. Hence, the mini lecture starts with a backward idea of giving a solution as graph or interval and ask the student to find the compound inequality of that graph. Once the instructor or teaching assistant discussed different scenarios with the students he or she asks them to solve question 3 and 4 and use question 1 to decide on the interval notation. Question 2 is considered a review and only used to idetify students who may need additional review.

1. Write a compound inequality for the graph shown below. Use $x$ for your variable.

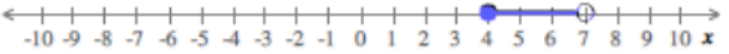

2. Solve the inequality for $v$.

$$
v+\frac{1}{5} \geq-\frac{2}{3}
$$

Simplify your answer as much as possible.
3. Solve the compound inequality.

$$
2 v-3>-11 \text { and } 4 v+5 \geq 29
$$

Write the solution in interval notation. If there is no solution, enter $\varnothing$.

4. Solve the compound inequality.

$$
3 y-5 \leq-23 \text { or } 2 y-2 \leq-4
$$

Write the solution in interval notation. If there is no solution, enter $\varnothing$.

Figure 10. Sample in-class mini-lesson for students with low mastery of compound inequalities in the College Algebra course. Adapted from MAC1105C: College Algebra, by R. Ait Maalem Lahcen, 2019, Orlando, FL: University of Central Florida. Copyright 2019 by the University of Central Florida.

\section{Conclusion}

As instructors, instructional designers, and administrators, we attempt to facilitate the adaptive learning process so that the benefits of adaptive technologies can be maximized in the design and delivery of adaptive courses. Following a systems approach to course design, we define adaptive courses as those which have a portion of the overall online learning content delivered via an adaptive learning system. It customizes objective-driven content and assessments to create a personalized learning path for each student according to their knowledge, skills, and learning needs. In the design process, the instructor should expect to spend a good amount of time 1) chunking the materials into learning bits based on granular objectives, 2) authoring assessment items and detailed feedback, 3) selecting and mapping objectives and lessons that are aligned with the course goals and student needs, and 4) enhancing the course with variables and alternative content.

As for teaching with adaptive courses, the following list highlights some pedagogical best practices. An instructor should

1. understand how adaptive systems work, especially with how grades are calculated; 
2. review key domain-based learning analytics to get an overall understanding of student performances;

3. adopt a concept-based flexible teaching method that targets challenging concepts, not all concepts; and

4. provide personalized teaching interventions based on student-based learning analytics.

The use of adaptive learning in higher education is an emergent area for study. While the pedagogical approach is grounded in student-centered mastery learning theories, there is still limited evidence on how adaptive systems improve student performance and/ or reduce learning gaps (Anderson, 2019; Dziuban et al., 2017, 2018; Essa \& Laster, 2017; Weber, 2019). Our goal is to document best practices for adaptive implementation from our design and teaching experiences, and we encourage further experimentations to be conducted on the effectiveness of these best practices. We hope that the adaptive learning design framework and best teaching practices proposed in this field note could be implemented in other higher education institutions with any assortment of adaptive platforms. We also welcome responses and invitations from other institutions for future collaboration and research opportunities.

\section{Acknowledgements}

The lessons learned and best practices shared in this field note are drawn from the works of the course instructors and Personalized Adaptive Learning instructional designers at the University of Central Florida. In particular, the authors would like to express gratitude to the piloting faculty members, Dr. Tammy Muhs, Dr. Julie Hinkle, and Mr. Tarek Buhagiar, and the instructional designers, Ms. Kathleen Bastedo, Ms. Corrinne Stull, Ms. Debbie Kirkley, Ms. J essica Tojo, and Mr. J oseph Lloyd. 


\section{References}

Ait Maalem Lahcen, R. (2019). MAC1105C: College Algebra. Orlando, FL: University of Central Florida.

Aleven, V., Mclaren, B. M., Sewall, J ., \& Koedinger, K. R. (2009). A new paradigm for intelligent tutoring systems: Example-tracing tutors. International J ournal of Artificial Intelligence in Education, 19(2), 105- 154. Retrieved from http:// dl.acm.org/ citation.cfm?id=1734243.1734245

Anderson, J . (2019, November 4). Busting the top 5 myths about adaptive learning [Realizeit Blog]. Retrieved November 5, 2019, from Realizeit website: http:// blog.realizeitlearning.com/blog/top5-myths-about-adaptive-learning

Association of Public \& Land-Grant Universities. (2017a). Personalizing learning with adaptive courseware. Retrieved from http:// www.aplu.org/projects-and-initiatives/ personalized-learningconsortium/plc-projects/plc-adaptive-courseware/

Association of Public \& Land-Grant Universities. (2017b). APLU adaptive aourseware grant program: Approved adaptive courseware suppliers and products. Retrieved from https:// www.aplu.org/ projects-and-initiatives/personalized-learning-consortium/plcprojects/plc-adaptivecourseware/Approved_Adaptive_Courseware_Suppliers_and_Products_2017.pdf

Baker, R. S. (2016). Stupid tutoring systems, intelligent humans. International J ournal of Artificial Intelligence in Education, 26(2), 600-614. https:// doi.org/ 10.1007/ s40593-016-0105-0

Becker, S. A., Brown, M., Dahlstrom, E., Davis, A., DePaul, K., Diaz, V., \& Pomerantz, J . (2018). 2018 NMC Horizon report: 2018 Higher education edition. Retrieved from https:// library.educause.edu/resources/2018/8/2018-nmc-horizon-report

Brusco, R. (2018). Personalized learning at its best (Blog post). Edutopa. Retrieved from https:// www.edutopia.org/article/ personalized-learning-its-best

Buhagiar, T. (2018). Module 6: Simple linear regression. In QMB3200: Quantitative Business Tools II. Orlando, FL: University of Central Florida

CAST. (2018). Universal design for learning guidelines. Retrieved from http:// udlguidelines.cast.org

Center for Distributed Learning (2019). Types of courses at UCF. Retrieved from https:// cdl.ucf.edu/ support/student/modalities/

Chen, B. (2019). Module 5: Learner assessments. In EME6613: Instructional Systems Design. Orlando, FL: University of Central Florida.

Chen, B., Bastedo, K., Kirkley, D., Stull, C., \&Tojo, J . (2017, August) Designing personalized adaptive learning courses at the University of Central Florida (Eli Brief). EDUCAUSE Learning Initiative. Retrieved from https:// library.educause.edu/resources/2017/8/ designing-personalized- 
adaptive-learning-courses-at-the-university-of-central-florida

Dziuban, C., Moskal, P., J ohnson, C., \&Evans, D. (2017). Adaptive learning: A tale of two contexts. Current Issues in Emerging eLearning, 4(1), 3. Retrieved from https:// scholarworks.umb.edu/ciee/vol4/iss1/3

Dziuban, C., Moskal, P., Parker, L., Campbell, M., Howlin, C., \&J ohnson, C. (2018). Adaptive learning: A stabilizing influence across disciplines and universities. Online Learning, 22(3), 7- 39. Retrieved from https:// eric.ed.gov/ ?id=EJ 1191489

Deslauriers, L., McCarty, L. S., Miller, K., Callaghan, K., \& Kestin, G. (2019, September). Measuring actual learning versus feeling of learning in response to being actively engaged in the classroom. Proceedings of the National Academy of Sciences, 116(39), 19251-19257. https:// doi.org/ 10.1073/pnas.1821936116

Edsurge. (2016). Decoding adaptive. Pearson. Retrieved from https:// www.pearson.com/ corporate/ about-pearson/innovation/smarter-digital-tools/adaptivelearning.html

Edwards, M., J ohnson, D., Ford, C., Pugliese, L., Fritz, J ., \& Birk, S. (2017). From adaptive to adaptable: The next generation for personalized learning. IMS Global Learning Consortium. Retrieved from https:// www.imsglobal.org/ adaptive-adaptable-next-generation-personalized-learning

Essa, A. (2016). A possible future for next generation adaptive learning systems. Smart Learning Environments, 3(1), 16. https:// doi.org/ 10.1186/s40561-016-0038-y

Essa, A., \& Laster, S. (2017). Bloom's 2 Sigma problem and data-driven approaches for improving student success. In R. Feldman (Ed.), The first year of college: Research, theory, and practice on improving the student experience and increasing retention (pp. 212-246). Cambridge: Cambridge University. https:// doi.org/ 10.1017/9781316811764.009

Hinkle, J . (2017). Case study: Endocrine. In NUR3125: Pathophysiology for Nursing Practice. Orlando, FL: University of Central Florida.

Khosravi, H., Sadiq, S., \& Gasevic, D. (2020). Development and adoption of an adaptive learning system. In Proceedings of the 51st ACM Technical Symposium on Computer Science Education. Portland, OR. https:// doi.org/ 10.1145/3328778.3366900

Muhs, T. (2018). Equations with one variable. In MAC1055: College Algebra. Orlando, FL: University of Central Florida.

PavlikJ J, P., Brawner, K., Olney, A., \& Mitrovic, A. (2013). A review of learner models used in intelligent tutoring systems. In R. Sottilare, A. Graesser, X. Hu, and H. Holden (Eds.), Adaptive Tutoring Series: Vol. 1. Design Recommendations for Intelligent Tutoring Systems (pp. 39- 68). Orlando, Florida: U.S. Army Research Laboratory. Retrieved from https://www.researchgate.net/profile/Phil_Pavlik_Jr/publication/258883086_A_Review_of_L 
earner_Models Used_in_Intelligent_Tutoring_Systems/links/Odeec52950ce7f24c2000000/AReview-of-Learner-Models-Used-in-Intelligent-Tutoring-Systems.pdf

Pugliese, L. (2016, October 17). Adaptive learning systems: Surviving the storm (Blog post). EDUCAUSE Review. Retrieved from https:// er.educause.edu/articles/2016/10/adaptive-learning-systemssurviving-the-storm

Thompson, J . (2013). Types of adaptive learning. Retrieved from https:// www.scribd.com/document/351803604/Adaptive-Learning-Types-of-Adaptive-Learning

Weber, N. (2019). Adaptive learning: Understanding its progress and potential. Horizon Report: 2019 Higher Education Edition. Louisville, CO: EDUCAUSE. Retrieved from https:// library.educause.edu/resources/2019/4/2019-horizon-report

Willcox, K. E., \& Huang, L (2017). Network models for mapping educational data. Design Science, 3(18). Retrieved from https:// www.cambridge.org/ core/journals/ design-science/ article/ networkmodels-for-mapping-educational-data/ B144B697F0998F36C445054DCA4DEA4F

Yarnall, L., Means, B., \& Wetzel, T. (2016). Lessons learned from early implementations of adaptive courseware (SRI Project Nos. 21987 and 22997). California: SRI Education. Retrieved from https:// www.sri.com/sites/default/files/brochures/almap_final_report.pdf

\section{Athabasca} University

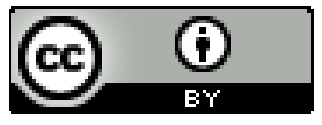

